\title{
Construction of Characteristic Discourse System of Ethnic Fine Arts Education in Ethnic Universities and Colleges
}

\author{
Xuemei Zhang \\ Southwest Min Minzu University, Chengdu, Sichuan, China \\ Aba Tea Teachers University, Aba, Sichuan, China \\ Email: snowzxm123@163.com
}

Keywords: Ethnic universities and colleges; Ethnic fine arts; Ethnic fine arts education; Aphasia phenomena.

\begin{abstract}
In order to promote the construction and reform of the characteristic discourse system of ethnic fine arts education in ethnic colleges and universities, and to strengthen the initiative of the education system itself, the phenomenon of "aphasia" of ethnic minority culture in the national fine arts education system in Chinese colleges and universities was investigated and analyzed. It is found that the "imbalance" of discourse standpoint and "loss of position" of the choice of educational value are the causes of aphasia in the development of art education for ethnic minorities in colleges. The position choice of "discourse" standpoint in national art education is closely related to the value orientation and the "context" of its educational value at the macroscopic social level. The choice of "discourse" in ethnic fine arts education is a choice of discourse position. In fact, the construction of "discourse" in ethnic fine arts education in ethnic colleges is a process of choosing whether to be "dissident" or "oneself", which is closely related to the "grammar" of the construction of educational value at the micro level. The construction and continuation of the "self" characteristics of ethnic fine arts education discourse need to clearly identify the attributes of the subject of the discourse on the "subjective" and adhere to the value standpoint of "self" of education. It is also necessary to construct the ecological "coordinate" of the continuation of "self" characteristics in the realistic fetters and contradictions of multiple value choices.
\end{abstract}

\section{Introduction}

As an important carrier for the continuation and development of the Chinese nation's culture, the development of higher education of ethnic fine arts in China is not only related to the overall construction and improvement of higher education of the fine arts system in China, but also relevant with the rise and fall of the Chinese nation and its multi-national culture [1]. It has established art education institutions for ethnic minorities at all levels, including art colleges and departments of ethnic universities, independent art colleges in ethnic areas, Art Majors of ethnic minorities in institutions of higher education in ethnic autonomous areas, and art institutes for ethnic minorities. It has also set up multi-level ethnic fine arts education systems covering doctoral, master's, undergraduate and higher vocational colleges and the number of students in school has increased hundreds of times. In the meantime, some ethnic fine arts educators and scholars have also studied and elucidated the related issues in the practice of ethnic fine arts education from different perspectives. However, these research results seem to largely neglect or even ignore the understanding of the essence of ethnic fine arts education, lack of a systematic and in-depth study of the problems of ethnic fine arts education. Therefore, the special research on the aphasia of ethnic fine arts education can not only reveal the essence of the problem, but also play a practical guiding role in the development of ethnic fine arts education $[2,3]$.

\section{Research status}

The data obtained from the search show that, this research status is very inconsistent with the 
objective reality of ethnic fine arts research and the development of ethnic fine arts education, and also reflects the current situation of "aphasia" in ethnic fine arts education research. In view of the relatively weak situation of the related theoretical research achievements of the ethnic fine arts education, the theoretical research achievements of other related disciplines are referred to, mainly involving the research on the ethnic higher education, the research on the field of ethnic fine arts education, aphasia phenomenon, and multi-cultural education theory four research fields.

Through sorting out the existing literature, it is found that the relevant research on the education of some ethnic groups will help us to clarify the essence and value of the ethnic fine arts education in colleges and universities. The study of aphasia in different disciplines will be helpful for us to grasp the deeper problems in the aphasia of the ethnic fine arts education. The research on the theory of multi-cultural education at home and abroad will undoubtedly provide a more instructive theoretical framework for the study of the problems of ethnic fine arts education. Meanwhile, it can be deeply felt that, compared with the educational theory of other disciplines, the exploration of educational theory of ethnic fine arts disciplines in colleges and universities still lags behind [4,5].

First, the research on the historical changes of the ethnic fine arts education is not enough. Although it has been nearly 60 years since the establishment and development of ethnic fine arts education in colleges and universities in China, the research on the historical changes of ethnic fine arts education in China is still very immature and the results are very few [6]. Secondly, the particularity of the ethnic fine arts education is very weak. Thirdly, the theoretical construction of ethnic fine arts education is basically blank, and the authority of relevant discourse is seriously inadequate. Fourthly, the research on the problem of "ethnic fine arts education" is mainly characterized by the description and discussion of problems. From the research methods of the existing literature, most of the current ethnic fine arts education is still in the intuitive "problem descriptive" mode of discussion, lack of deep concern about the problem itself, as well as reference and demonstration of related discipline educational theory [7].

\section{An analysis of the phenomenon of "aphasia" and its causes in the development of ethnic fine arts education in ethnic universities}

\subsection{Aphasia" phenomenon in the development of ethnic fine arts education in ethnic universities}

The objective is to investigate and analyze the practice of ethnic fine arts education in ethnic colleges and universities, reveal the situation of ethnic fine arts education practice in ethnic colleges and universities, accurately grasp the existing problems in the practice of ethnic fine arts education, find out the defects in the system of ethnic fine arts education, and explore the objective law of the healthy development of the higher education of ethnic fine arts, so as to provide some beneficial references for the reform and development of the ethnic fine arts education in the new period. 5 representative ethnic universities are selected to summarize their problems.

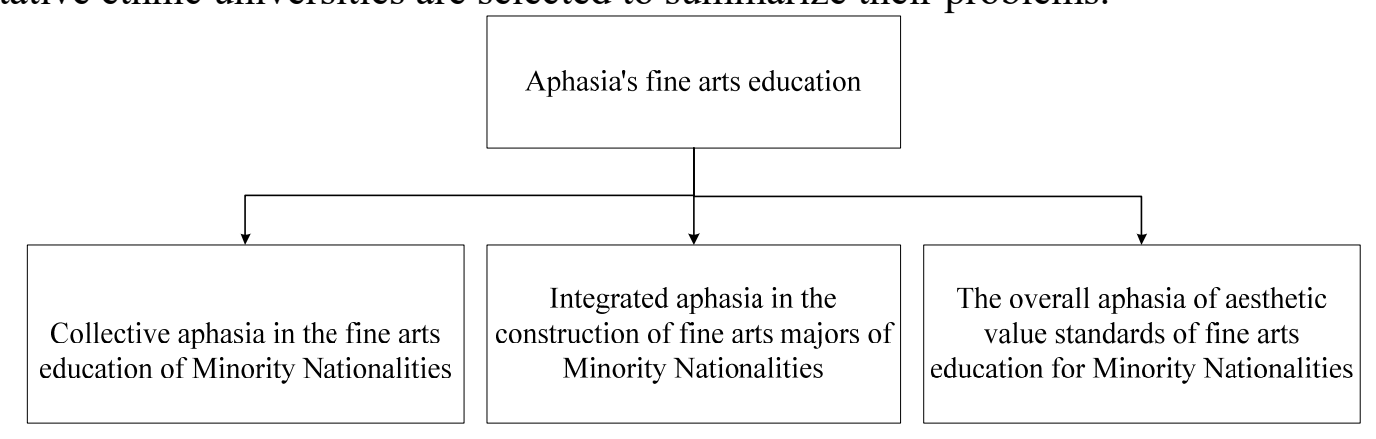

Figure 1 Expression of aphasia in ethnic fine arts education.

\subsection{An analysis of the causes of "aphasia" in the development of ethnic fine arts education in ethnic universities}

The culture and art of any country or nation have its value standards derived from its historical 
development. This ethnic aesthetic determines the orientation of its cultural and artistic development and its status in human history. That is to say, if a country or a nation's culture and art have no distinct regional or national characteristics, there will be no vitality and no value as an independent cultural system. Through combing the development history of ethnic fine arts education in ethnic colleges and universities and investigating the present situation and effect of the implementation of ethnic fine arts education, it can clearly see the "loss of location" of the value of ethnic fine arts education in the fine arts education system in ethnic colleges and universities and "imbalance" of the contemporary standard (value orientation) of ethnic fine arts education in China in the course of its actual development. It can be said that the "absence" of the value and standard of ethnic fine arts education in China is the key to the phenomenon of "aphasia" in the development of ethnic fine arts education. And what is the value criterion of the ethnic fine arts education? What has contributed to the current "aphasia" of the ethnic fine arts education system?

Discourse is the expression of a "standpoint" of related culture. It is not only about the understanding of a certain cultural form, but also based on the value identification and choice of this culture. In this era, once many "discourse" formed, they will pass on a certain "specific" value, with some "specific" regulations, and also building a "specific" knowledge system and value system. The choice and persistence of values are the basis for the inheritance and innovation of the "discourse" of ethnic fine arts education. The cultural accumulation of different regions and different nationalities breeds different forms of art and distinctive culture.

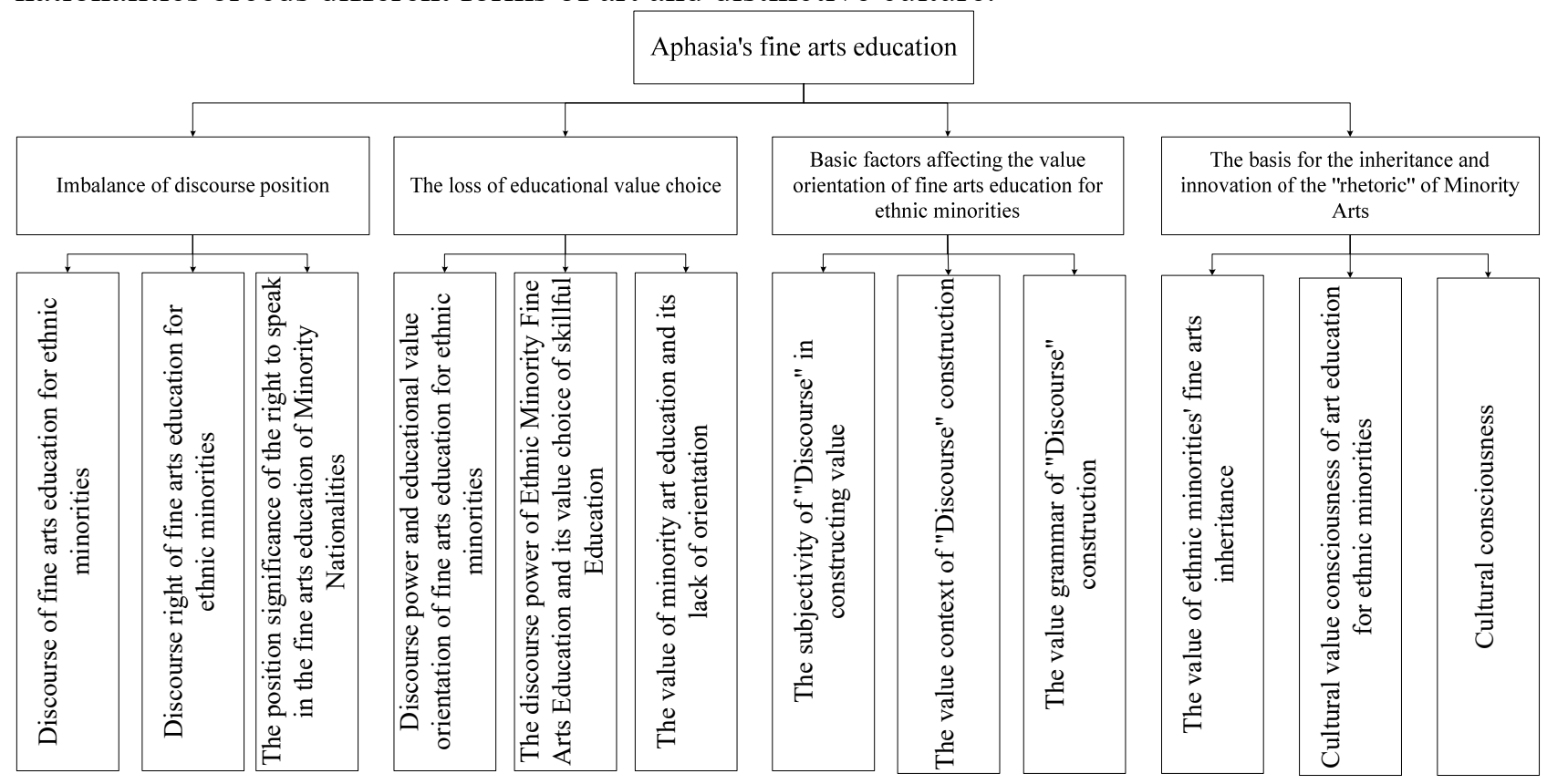

Figure 2 Causes for "aphasia" in the development of ethnic fine arts education in ethnic universities and colleges.

\section{The relationship between the discourse subject of ethnic fine arts education in ethnic universities and the construction of educational "discourse"}

\subsection{Discourse subject and relationship of ethnic fine arts education in ethnic universities}

If, from a macro perspective, the cause of "aphasia" in the development of ethnic fine arts education is a dispute over the "discourse right" arising from the "value" of ethnic art education, then for ethnic colleges and universities, as the subject of the "discourse" dissemination of ethnic fine arts education, in the process of implementation of training talents for ethnic fine arts, what are the practical difficulties? Based on the direct nature of the environment under which the research object belongs and the richness and diversity of ethnic minorities in China, the Academy of Fine Arts of Central South University for Nationalities is chosen to make a concrete analysis in order to explore the specific problems of constructing the standard of "discourse" on the micro-level of the 
phenomenon of "aphasia" in ethnic fine arts education.

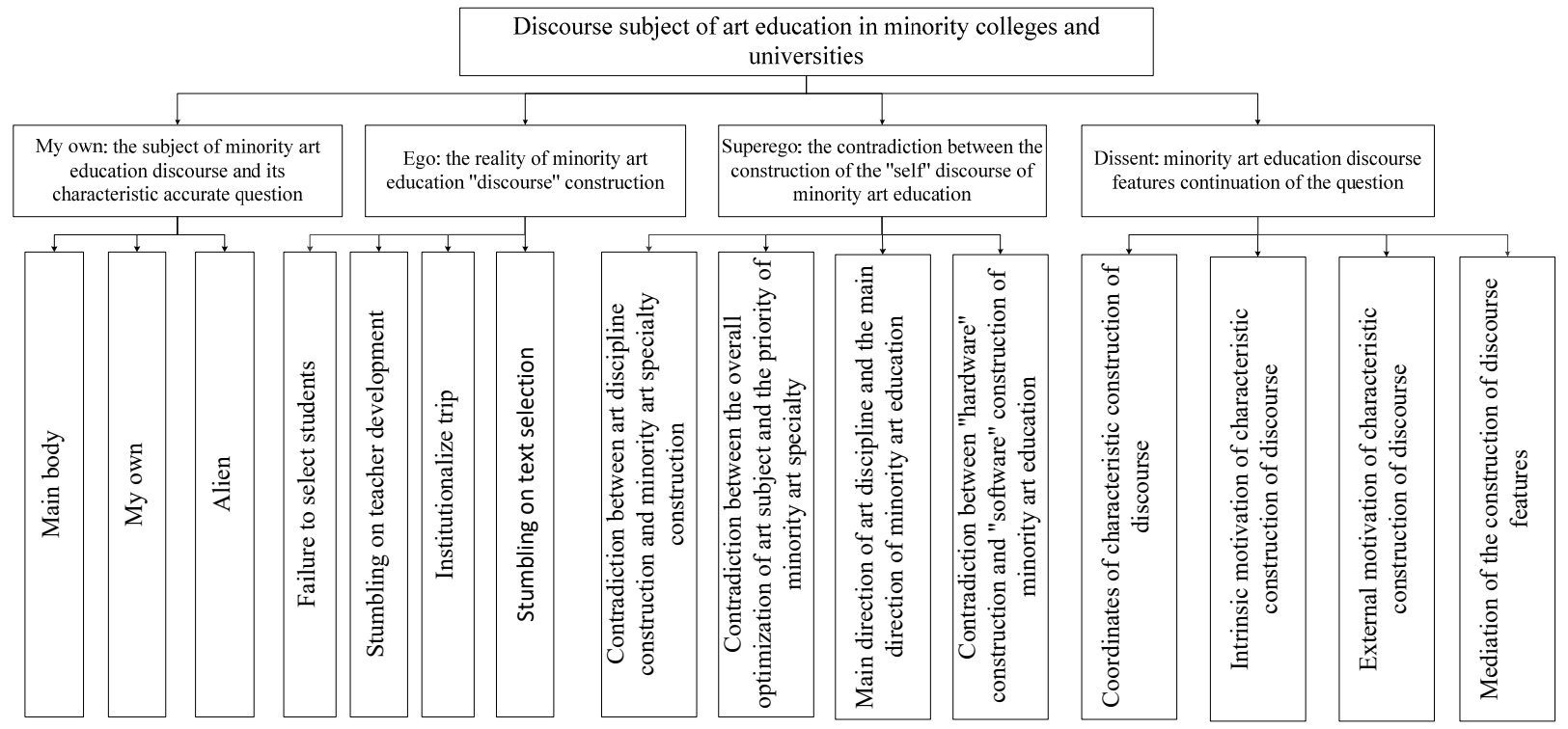

Figure 3 Discourse subject of ethnic fine arts education in ethnic colleges and universities and its relationship perspective.

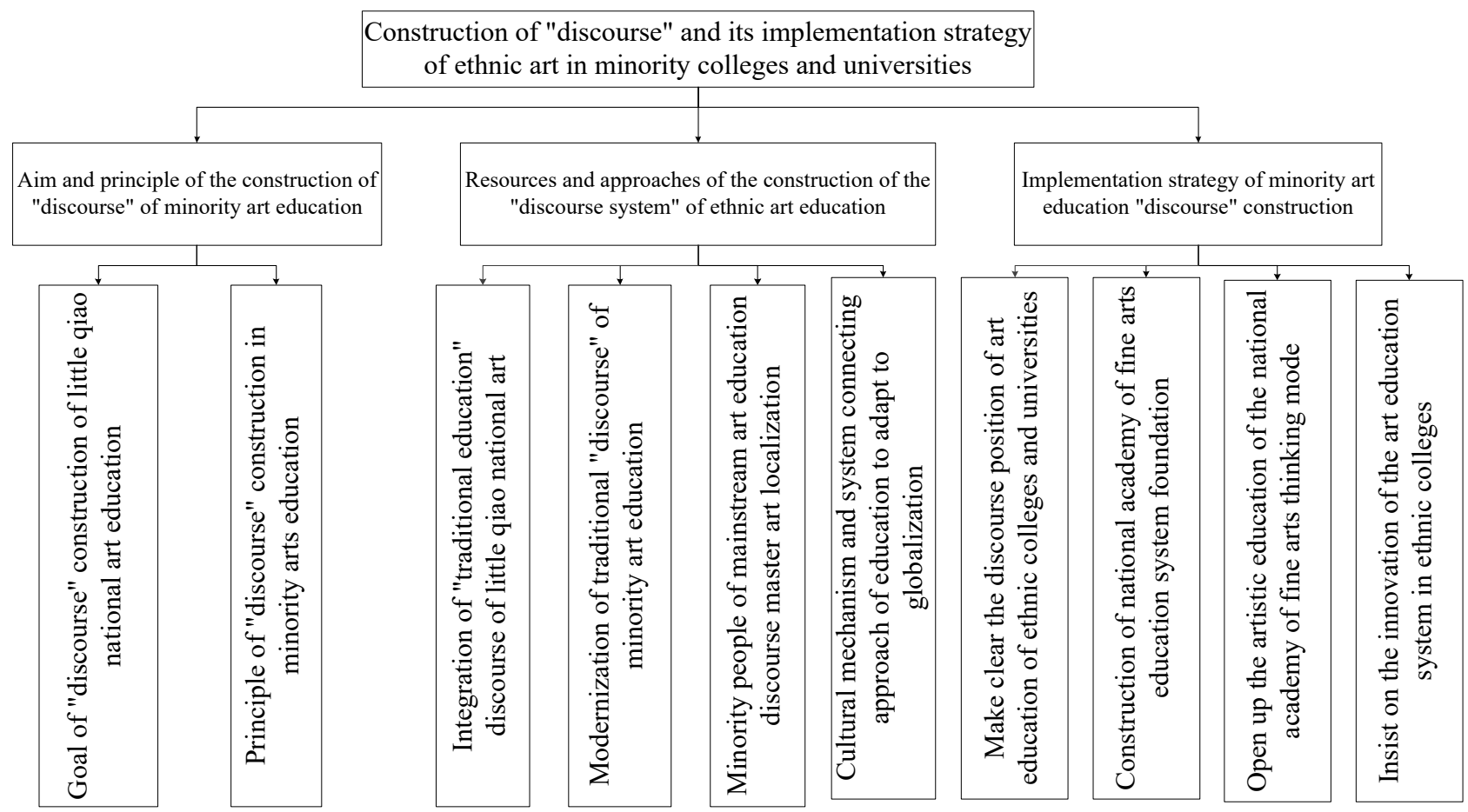

Figure 4 Construction of "discourse" and its implementation strategy of ethnic fine arts education in ethnic colleges and universities.

\subsection{Construction and implementation strategy of "discourse" of ethnic fine arts education in ethnic universities and colleges}

The construction of "discourse" in higher education is the premise and foundation for establishing "discourse right" in the educational theory and practice for a country, a nation, or a class. The existence and strength of discourse system are related to the status of a country or a nation in international relations. In the domestic relations, it relates to the political and economic status of a class or ethnic group, and reflects whether it has the initiative or the guidance power in the fields of ideology and culture. The construction of the "discourse" system of ethnic fine arts education is, on the surface, a linguistic expression of "what to say and how to say" in the 
implementation of higher education in colleges and universities. In essence, it is also a major issue involving the ideological identification, value standpoint, thinking mode and other aspects of college education. When it comes to how to strengthen the cultural consciousness and cultural selfconfidence of ethnic fine arts education, where does this self-consciousness and self-confidence come from? On the one hand, one of the most important aspects is to have a set of their own educational discourse system to support, so that they can speak with confidence and others also sound convinced. On the other hand, it is necessary to have the courage to take on the spirit and the courage to dialogue, rely on their own discourse system platform advantages, make their own voice, and express them, so that others can understand them.

\section{Conclusion}

A comprehensive and systematic analysis is made of the context and data consideration of ethnic fine arts education in different types of ethnic colleges and universities. Moreover, a thorough analysis is made of the "common causes" of aphasia in the development of ethnic fine arts education in Chinese ethnic colleges and universities. It is found that the "unbalance" of discourse standpoint and the "loss of location" of educational value choice are the only causes of aphasia in the development of ethnic fine arts education in ethnic universities and colleges. In practice strategy, based on the "multi-dialog" perspective of ethnic fine arts education discourse in ethnic colleges and universities, combined with the realistic "context" of globalization and marketization of education, the construction objectives, principles, and the resource paths of the construction of the discourse system of ethnic fine arts education discourse are defined from four dimensions: social value, educational value, multi-cultural value and development mechanism. The multi-level and three-dimensional practice strategy and mode of "discourse" in the cross-cultural education of ethnic fine arts education is also constructed.

\section{References}

[1] Byun, M. A., Inkelas, S., \& Rose, Y. (2016). The a-map model: articulatory reliability in childspecific phonology. Language, 92(1), 193-192.

[2] Hernándezsacristán, C., \& Serraalegre, E. (2016). On the metacognitive dimension of suspended syntactic constructions. A descriptive study on aphasic Spanish speakers. Revista De Investigacion En Logopedia, 1(1), 42-69.

[3] Baqué L. (2017) Lexical stress contrast marking in fluent and non-fluent aphasia in Spanish: The relationship between acoustic cues and compensatory strategies. Clin Linguist Phon, 1-23.

[4] Jackendoff, R., \& Wittenberg, E. (2017). Linear grammar as a possible stepping-stone in the evolution of language. Psychon Bull Rev, 24(1), 219-224.

[5] Tsai, T. (2017). Prb leading the hewlett foundation's poppov initiative. Research in Science \& Technological Education, 14(1), 5-20.

[6] Stylianou, A. (2017). Absenting the absence(s) in the education of poor minority ethnic students: a critical realist framework. International Journal of Inclusive Education, 21(33), 1-16.

[7] Gummadam, P., Pittman, L. D., \& Ioffe, M. (2016). School belonging, ethnic identity, and psychological adjustment among ethnic minority college students. Journal of Experimental Education, 84(2), 289-306. 